(2) Open Access Full Text Article

\title{
Longitudinal burnout-collaboration patterns in Japanese medical care workers at special needs schools: a latent class growth analysis
}

This article was published in the following Dove Press journal:

Psychology Research and Behavior Management

14 June 2016

Number of times this article has been viewed

\author{
Mieko Kanayama' \\ Machiko Suzuki' \\ Yoshikazu Yuma² \\ 'Department of Human Health \\ Sciences, Kyoto University Graduate \\ School of Medicine, Kyoto, Japan; \\ ${ }^{2}$ Department of Human Development \\ Education, Graduate School of \\ Education, Hyogo University of \\ Teacher Education, Kato, Hyogo, Japan
}

Correspondence: Mieko Kanayama Department of Human Health Science, Kyoto University Graduate School of Medicine, 53 Kawahara-cho, Shogoin, Sakyo-ku, Kyoto 606-8507, Japan $\mathrm{Tel}+8 \mathrm{I} 05685 \mathrm{I} 9406$ Fax +810568514699

Email kanayama.mieko.56s@st.kyoto-u.ac.jp

\begin{abstract}
The present study aimed to identify and characterize potential burnout types and the relationship between burnout and collaboration over time. Latent class growth analysis and the growth mixture model were used to identify and characterize heterogeneous patterns of longitudinal stability and change in burnout, and the relationship between burnout and collaboration. We collected longitudinal data at three time points based on Japanese academic terms. The 396 study participants included academic teachers, yogo teachers, and registered nurses in Japanese special needs schools. The best model included four types of both burnout and collaboration in latent class growth analysis with intercept, slope, and quadratic terms. The four types of burnout were as follows: low stable, moderate unstable, high unstable, and high decreasing. They were identified as involving inverse collaboration function. The results indicated that there could be dynamic burnout types, namely moderate unstable, high unstable, and high decreasing, when focusing on growth trajectories in latent class analyses. The finding that collaboration was dynamic for dynamic burnout types and stable for stable burnout types is of great interest. This was probably related to the inverse relationship between the two constructs.
\end{abstract}

Keywords: burnout, collaboration, latent class growth analysis, interprofessional care, special needs schools

\section{Introduction}

Preventing burnout is an important issue for both nurses and teachers. ${ }^{1,2}$ Registered nurses are currently fighting an uphill battle against burnout. Dr Linda Aiken, Director of the Center for Health Outcomes and Policy Research, remarked on this issue. ${ }^{3}$ School nurses are particularly vulnerable to burnout, because they are involved in complex, frontline clinical work. ${ }^{4}$ Teachers have also shown high levels of exhaustion and cynicism as symptoms of burnout. ${ }^{5,6}$ In Japan, Motomura and Yatsushiro reported that the rate of burnout in hospital-based nurses was twice that of general physicians. In addition, Arai $^{8}$ found that the number of teachers experiencing burnout had increased rapidly. However, there have been no studies conducted to examine burnout in school nurses.

Burnout is defined as a syndrome that involves physical and emotional exhaustion in service professionals. The most widely used definition is that of Maslach, ${ }^{9}$ who described psychological burnout as a syndrome consisting of three characteristics: emotional exhaustion, depersonalization, and reduced personal accomplishment.

Collaboration has attracted interest as a primary factor in the suppression of burnout. Onyett ${ }^{10}$ found that burnout was low in staff who reported high levels of team 
role clarity and identification, both of which are important factors in collaboration in community mental health teams. Rafferty et al $^{11}$ suggested that good human relationships between nurses and physicians prevented burnout. In Japan, Ogino $^{12}$ posited that human relationships between nurses and other professionals constitute an important factor in burnout in hospitals. In addition, Katsuda ${ }^{13}$ reported that insufficient collaboration between nurses and teachers, with respect to medical care in Japanese schools, was likely to cause nurses to retire. However, no studies have focused on the relationship between burnout and collaboration in school nurses and teachers.

Much of the literature has suggested that burnout is progressive. ${ }^{14-17}$ Dunford et $\mathrm{al}^{18}$ focused on the progressiveness of burnout in employees working in health care organizations in the United States, using five measurement points over a 2-year survey period. They found that burnout was relatively stable in organizational insiders, but was slightly dynamic in newcomers and job changers, assuming homogeneity within employment types. These findings indicated that levels of burnout changed for some but not for others.

There are individual differences in burnout. Individual perspectives on burnout stress the role of certain factors and processes within the individual. ${ }^{6}$ Golembiewski and Munzenrider ${ }^{19}$ found that individuals could be classified into high- or low-burnout groups in three subdomains of the Maslach Burnout Inventory (MBI). Using the MBI General Survey, Montero-Marin et $\mathrm{al}^{20}$ also found that individuals with burnout were categorized into the following three clinical subtypes: frenetic (involved, ambitious, and overloaded), underchallenged (indifferent, bored, and lacking personal development), and worn out (exhausted and tired out). These results indicated heterogeneity in burnout. However, previous research did not characterize longitudinal individual differences in burnout or the relationship between burnout and collaboration.

Traditionally, longitudinal studies have used variablecentered approaches such as regression, factor analysis, or structural equation modeling and focused on describing the relationships between variables over time. However, given that research has shown that there are individual differences in burnout, which presumably vary over time, the present study used the person-centered approaches, latent class growth analysis (LCGA), and growth mixture modeling (GMM). The method used was similar to cluster analysis, because it categorizes people into subgroups, with each subgroup representing individuals who follow a similar developmental course for a particular variable. In general, the goal of this method is to classify individuals into distinct groups based on individual response patterns and to ensure that individuals within each group are more similar than those between groups. ${ }^{21,22}$ Therefore, the method is designed to capture information regarding interindividual differences in intra-individual change over time by taking unobserved heterogeneity (different groups) within a larger population ${ }^{21,22}$ into account. The approach has also been useful in similar research such as examining coping. ${ }^{23}$ To the best of our knowledge, the method has not been used in research examining burnout.

Using person-oriented approaches, the present study aimed to identify and characterize potential burnout types and the relationship between burnout and collaboration over time. This study used LCGA and the GMM to identify and characterize heterogeneous patterns of longitudinal stability and change in burnout, and the relationship between burnout and collaboration. Given that special needs schools typically include medical care teams, we were able to identify Japanese schools with academic teachers, yogo teachers, and registered nurses. Yogo teachers occupy a unique educational position in Japanese schools and hold a license to teach health and manage health care for students and school staff. The participants were assessed for burnout and collaboration three times over the course of a year. Using LCGA and the GMM, we hypothesized that there would be various burnout types showing different longitudinal patterns according to the level of collaboration present.

\section{Method \\ Participants}

As the Ministry of Education does not publish the names of special needs schools that provide medical care in Japan, we identified 382 special needs schools that provide medical care, by sending letters to the schools to inquire as to whether they provided such care. Of the initial 382 schools, 144 participated in the survey. School staff included academic teachers, yogo teachers, and registered nurses, and 432 staff members were recruited from 144 special needs schools. Responses were received from 399 individuals from 141 special needs schools; however, 1 individual was excluded because consent to participate could not be confirmed, and 2 were excluded because data concerning their birth dates were absent. Ultimately, data from 396 individuals were included in the analysis (collection rate: $92.4 \%$, valid response rate: $99.2 \%$ ). The second and third waves included data from 367 and 348 individuals, respectively. Approximately 23\% of the 615 special needs schools implementing medical care in Japan in 2012 (Ministry of Education, Culture, Sports, Science and Technology in Japan, 2013) ${ }^{24}$ participated in the study. 
Three types of professionals are engaged in medical care in Japanese special needs schools. The Japanese school year begins in April, ends in March of the following calendar year, and includes three academic terms. Longitudinal data were collected at three time points based on these academic terms: the end of the first term (August 2013), the end of the second term (December 2013), and the end of the third term (March 2014).

We informed the study participants in writing that participation in the study was entirely voluntary and that their data would not be used for purposes other than research. Participants confirmed their intent to participate by signing the agreement. Ethical approval for the study was granted by the ethics committee of Kyoto University Graduate School of Medicine.

Confidentiality, anonymity, and participation withdrawal were discussed with participants prior to their provision of written informed consent.

\section{Assessment}

\section{Burnout}

We used the Japanese version of the MBI scale ${ }^{25}$ developed by Kubo, ${ }^{26}$ which has been used in burnout research by numerous researchers worldwide, leading to the accumulation of a large body of research involving the scale. The Japanese version of the MBI was used in the current study because it is the most frequently used scale in burnout research in Japan, and the reliability and validity of the scale have been verified. The scale consists of three subscales: emotional exhaustion (five items), depersonalization (six items), and reduced personal accomplishment (six items). All items are rated on a 5-point Likert-type scale ranging from 1 (never) to 5 (always). Scores for the subscales are calculated by dividing the total scores by the number of items. In the Japanese version of the MBI, total scores range from 3 to 15 and are calculated by adding the total scores for the three subscales. We used a four-stage model of burnout, which was developed by Tao and $\mathrm{Kubo}^{27}$ and based on the Japanese version of the MBI, to assess participants' burnout. In a study examining burnout in Japanese nurses, Tao and Kubo compared scores on the Japanese version of the MBI with strength of turnover intention, which is measured using the question "Do you want to change your position at work or continue as a nurse?" Turnover intention was evaluated according to four stages based on responses to this question: Stage 1: "Things are fine the way they are", Stage 2: "I want to switch units", Stage 3: "I want to switch hospitals", and Stage 4: "I want to quit nursing". Tao and Kubo asserted that at Stage 4, characterized by a desire to withdraw from one's job, tension that peaked during Stage 3 is suddenly released, and feelings of pride and responsibility concerning work are lost. Based on this work, we considered participants to have reached burnout if their burnout scores placed them at the final stage. Based on Tao and Kubo's work, we calculated the burnout scale score ranges for Stages 1 (3.00-7.40), 2 (7.41-7.80), 3 (7.81-11.80), and 4 (11.81-15.00). We then defined high, moderate, and low levels of burnout as representative of participants having reached Stage 3 or 4, 2, and 1, respectively.

\section{Collaboration}

We used the Nurse-Teacher Collaboration Scale ${ }^{28}$ to measure the extent of participants' collaboration achievement. The scale was developed to measure achievement of collaboration between medical care workers in Japanese special needs schools ${ }^{28}$ and originally referenced the theory of San Martin-Rodriguez et al. ${ }^{29}$ The scale consists of three subscales: satisfaction with school organization and system for medical care (13 items), satisfaction with the respect shown for professional expertise (7 items), and satisfaction with daily communication ( 8 items). All items were rated on a 4-point Likert-type scale ranging from 1 (strongly disagree) to 4 (strongly agree). Scores for the subscales are calculated by adding the scores for each item. Total scores range from 28 to 112 and are calculated by adding the total scores for the three subscales. The reliability and validity of the scale were verified by Kanayama and Iwai. ${ }^{28}$

\section{Analyses}

We determined how workers' burnout and collaboration altered over the academic terms using LCGA, which is a variant of structural equation modeling that explains change and its form across time as an underlying latent process, and the GMM. ${ }^{21}$ GMM, an extension of LCGA, allowed us to assess individual differences in the same latent class. ${ }^{30}$ The LCGA and GMM analyses were performed using the M-plus statistical package (version 7) (Muthén and Muthén, Los Angeles, CA, USA). ${ }^{30}$ The missing data method (ie, E-M algorithm assuming that data are missing at random) was used, which allowed us to include all observations in the dataset in the estimation of the model parameters without imputing data. ${ }^{31,32}$ The following three different types of growth trajectory were estimated:

1. Intercept model: the workers' burnout and collaboration do not change across the terms.

2. Intercept and slope model: the workers' burnout and collaboration change linearly across the terms. 
3. Intercept, slope, and quadratic model: the workers' burnout and collaboration change curvilinearly across the terms.

Models were estimated using two variables (burnout and collaboration), two statistical models (LCGA and GMM), three growth trajectories, and five (max) latent classes. Goodness of fit for the resulting 60 models was captured via the Bayesian information criterion (BIC; Schwartz), ${ }^{33}$ with a lower BIC indicating a more parsimonious model fit. In addition, model selection was guided by evaluation of model classification accuracy, with entropy values closer to 1 (range $0-1$ ) indicating greater precision. In the results section, we present 1) demographics with descriptive statistics, 2) best-fit model and data related to the model (BIC and entropy), and 3) characterization of burnout patterns and the relationship between burnout and collaboration.

\section{Results}

Cronbach's $\alpha$ s for the burnout and collaboration scales were 0.85 and 0.88 for the first term, 0.81 and 0.82 for the second term, and 0.83 and 0.89 for the third term, respectively.

\section{Demographics}

The proportions of academic teachers, yogo teachers, and nurses were almost identical. Most participants were women (Table 1), and their average age was $43.7 \pm 9.5$ (standard deviation) years. Mean scores for burnout were moderate (eg, 7.0-7.6 out of a possible 15; Table 2) regardless of the time at which they were recorded. Mean collaboration scores were slightly high (eg, 70.7-73.2 out of a possible 112; Table 2) regardless of the time at which they were recorded.

\section{Best-fit model}

Table 3 shows the best-fit model, which demonstrated the lowest BIC $(12,167.55)$ and largest entropy $(0.74)$ of all of the models. This indicates that the best model fits the data fairly well. It also contained all four pattern types (low stable,

Table I Descriptive statistics ( $N=396)$

\begin{tabular}{lll}
\hline & $\mathbf{n}$ & $\%$ \\
\hline Sex & & \\
Male & 23 & 5.8 \\
$\quad$ Female & 372 & 94.2 \\
Occupation & & \\
$\quad$ Nurses & 145 & 36.6 \\
Teachers & 127 & 32.1 \\
Yogo teachers & 124 & 31.1 \\
Age (mean, SD) & 43.7 & 9.5 \\
\hline
\end{tabular}

Abbreviation: SD, standard deviation.
Table 2 Descriptive statistics for burnout and collaboration $(\mathrm{N}=396)$

\begin{tabular}{llll}
\hline & $\mathbf{n}$ & Mean & SD \\
\hline Burnout I wave & 396 & 7.1 & 1.5 \\
Burnout 2 wave & 367 & 7.0 & 1.4 \\
Burnout 3 wave & 348 & 7.6 & 1.5 \\
Collaboration I wave & 396 & 70.7 & 9.2 \\
Collaboration 2 wave & 367 & 73.1 & 10.6 \\
Collaboration 3 wave & 348 & 73.2 & 9.9 \\
\hline
\end{tabular}

Abbreviation: SD, standard deviation.

moderate unstable, high unstable, and high decreasing), which are presented in Figure 1.

\section{Low-stable type}

The low-stable type initially showed low-to-moderate burnout and moderate-to-high collaboration, which remained stable across the three terms (Figure 2). Burnout scores remained at Stage 1 throughout the year, while collaboration scores were slightly higher than average at the beginning of the year and remained as such throughout the year. This type comprised $64.1 \%$ of the participants.

\section{Moderate-unstable type}

The moderate-unstable type initially showed low-to-moderate burnout, which fluctuated between high and low scores across the terms. Collaboration scores showed inverse function, in that they were initially high and fluctuated between low and high across the terms (Figure 3). Burnout scores were at Stages 2, 3, and 1 in the first, second, and third semesters, respectively. Collaboration scores were slightly below average at the beginning of the year, fell considerably to well below average in the second semester, and rose to average levels in the third semester. This type comprised $16.2 \%$ of the participants.

\section{High-unstable type}

The high-unstable type initially showed high-to-moderate burnout, which fluctuated between high and low scores across the terms. Collaboration scores showed inverse function, in

Table 3 Results of the latent class growth analysis $(\mathrm{N}=396)$

\begin{tabular}{|c|c|c|c|c|c|c|}
\hline & \multirow{2}{*}{\multicolumn{2}{|c|}{$\begin{array}{l}\text { Number } \\
\text { of classes }\end{array}$}} & \multicolumn{4}{|c|}{ Burnout (quadratic slope) } \\
\hline & & & I & 2 & 3 & 4 \\
\hline \multirow{6}{*}{$\begin{array}{l}\text { Collaboration } \\
\text { (quadratic } \\
\text { slope) }\end{array}$} & $\mathrm{BIC}$ & I & & $12,225.57$ & $12,176.75$ & $12,168.79$ \\
\hline & Entropy & & & 0.72 & 0.70 & 0.74 \\
\hline & $\mathrm{BIC}$ & 2 & $12,238.39$ & $12,167.55$ & $12,180.25$ & $12,205.59$ \\
\hline & Entropy & & 0.72 & 0.74 & 0.70 & 0.71 \\
\hline & $\mathrm{BIC}$ & 3 & $12,180.46$ & $12,184.98$ & $12,211.96$ & $12,261.64$ \\
\hline & Entropy & & 0.70 & 0.73 & 0.70 & 0.74 \\
\hline
\end{tabular}

Abbreviation: BIC, Bayesian information criterion. 


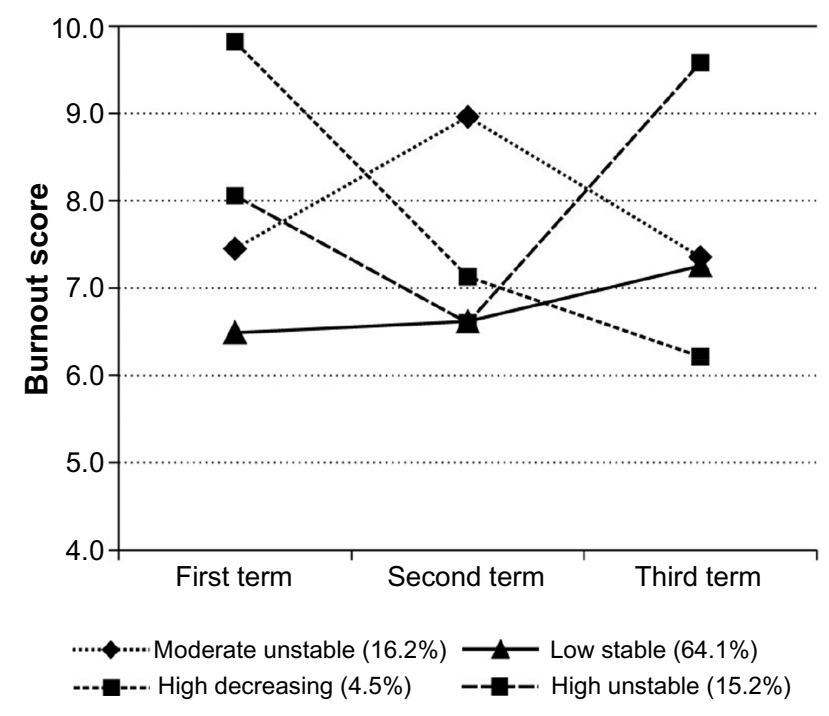

Figure I Growth trajectories for burnout.

that they were initially low and fluctuated between low and high across the terms (Figure 4). Burnout scores were at Stages 3, 1, and 3 in the first, second, and third semesters, respectively. Collaboration scores were below average at the beginning of the year, rose considerably in the second semester, and fell below average again in the third semester. This type comprised $15.2 \%$ of the participants.

\section{High-decreasing type}

The high-decreasing type initially showed high-to-low burnout, which decreased across the terms. Collaboration scores showed inverse function, in that they were initially low and increased across the terms (Figure 5). Burnout scores were at Stages 3, 1, and 1 in the first, second, and third semesters, respectively. Collaboration scores were

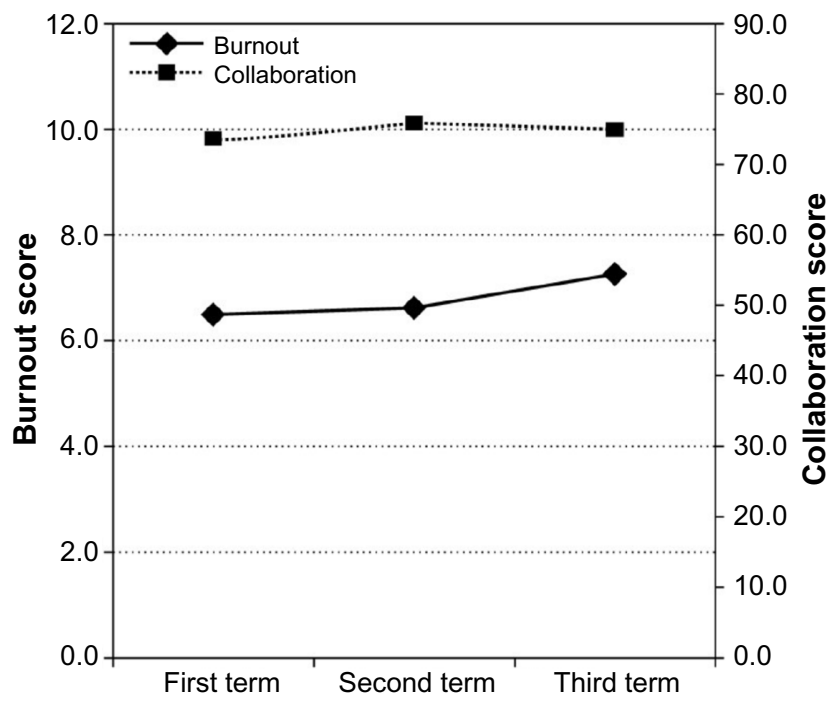

Figure 2 Growth trajectories of burnout and collaboration for the low-stable type.

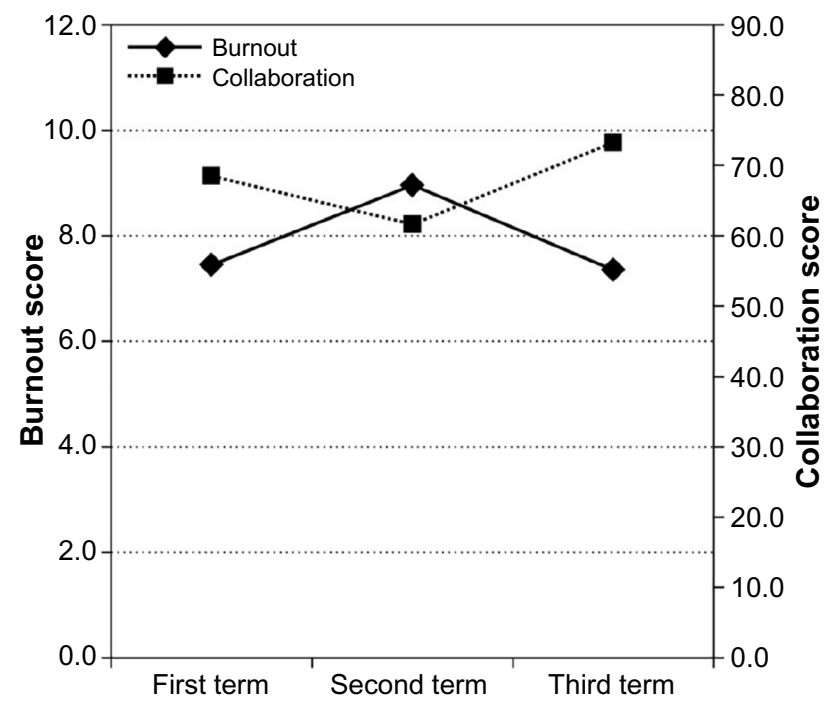

Figure 3 Growth trajectories of burnout and collaboration for the moderateunstable type.

well below average at the beginning of the year, increased to average levels in the second semester, and rose above average levels in the third semester. This type comprised $4.5 \%$ of the participants.

\section{Discussion}

We assessed many models that varied with respect to the co-occurrence of burnout and collaboration, based on the assumption of two statistical models (LCGA and GMM), three growth trajectories (intercept, slope, and quadratic), and five $(\max )$ latent classes. The best model contained four types of both burnout and collaboration in the LCGA with intercept, slope, and quadratic terms. The four types of burnout were low stable, moderate unstable, high unstable,

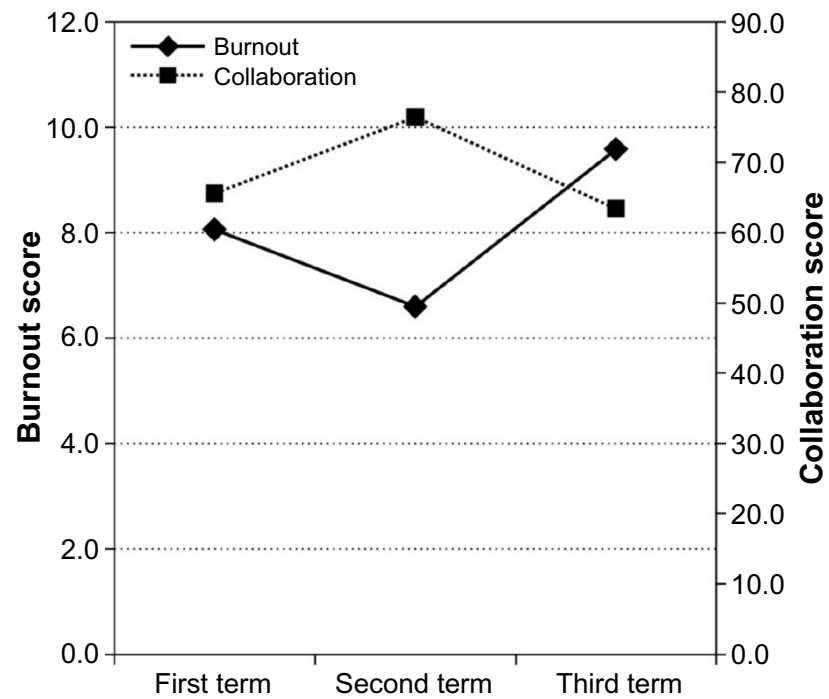

Figure 4 Growth trajectories of burnout and collaboration for the high-unstable type. 


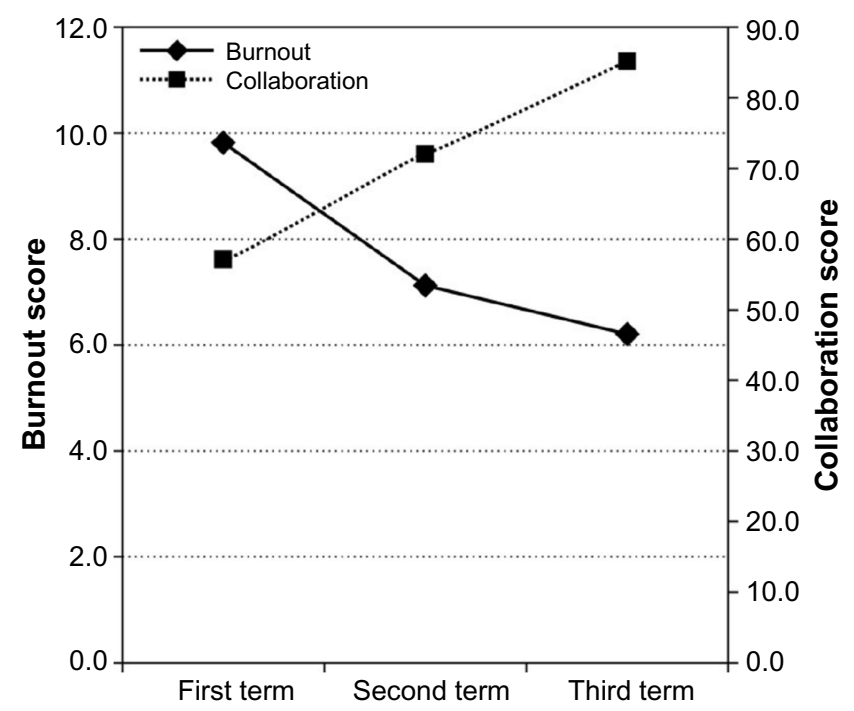

Figure 5 Growth trajectories of burnout and collaboration for the high-decreasing type.

and high decreasing. They were identified as having an inverse collaboration function (Figures 2-5). With regard to burnout alone, some participants exhibited dynamic change, while others were stable, which is consistent with the findings reported by Dunford et al. ${ }^{18}$ Although this study was the first to examine growth trajectories for collaboration in a similar manner to those of burnout, there appeared to be both dynamic and stable collaboration types.

Previous cross-sectional studies have identified only two categories. Using the LCGA/GMM method to identify heterogeneous patterns of longitudinal stability and change in burnout, four types emerged. This suggests that there may be dynamic burnout types, namely moderate unstable, high unstable, and high decreasing, when focusing on growth trajectories in the latent class analysis.

Previous studies have demonstrated that the relationship between burnout and collaboration shows inverse function. ${ }^{10,11}$ Halbesleben ${ }^{34}$ and Lee and Ashforth ${ }^{35}$ stated that multidisciplinary collaboration and burnout are closely related. The current findings extend these results to show that this inverse function continues across time. The finding that collaboration is dynamic for dynamic burnout types and stable for stable burnout types is of great interest. This is probably related to the inverse relationship between the two constructs.

Individuals exhibiting low-stable and high-decreasing types of burnout are most likely to be at the least risk for burnout affecting quality of life. Low burnout risk is most likely due to high or increasing collaboration between team members. Previous studies have shown that increasing collaboration benefits not only the recipient (patient or student) but also the participant (nurse or teacher). Chang et $\mathrm{al}^{36}$ found that collaboration between health care professionals improved job satisfaction in staff. Katsuda ${ }^{13}$ and Shimizu ${ }^{37}$ reported that sufficient collaboration between nurses and teachers, with respect to medical care in Japanese schools, is likely to prevent retirement in nurses and reduce work-related worry in teachers. With successful collaboration, individuals exhibiting this type may continue to work without experiencing burnout, which could improve circumstances for both recipients and participants.

With regard to unstable types, while it is unclear whether collaboration fluctuates according to burnout or vice versa, this fluctuation is likely to result in greater risk due to instability or lack of improvement over time. Based on burnout scores, participants considered to be at high risk of burnout exhibited the high-unstable type (15.2\%), with average burnout scores at Stage 3 in the third semester. Burnout scores for some participants exhibiting the moderate-unstable and highdecreasing types placed them at Stage 3 during the first or second semesters, but because the average score for both these types fell to that of Stage 1 in the third semester, they were considered to be at low risk of burnout. Previous research has shown that instability or lack of collaboration is related to high burnout and worsens quality of life. ${ }^{34,35}$ Recently, Martinussen et al's ${ }^{38}$ model of burnout, using hierarchical multiple regression analysis, demonstrated that collaboration outcomes predict work motivation and quality of services. Individuals exhibiting the high-unstable type are more likely to experience burnout and fail in collaboration; as a result, teachers, nurses, and yogo teachers may lose motivation at work, which could reduce the quality of the service they provide.

The current results showed that those named the highunstable type began with high burnout at the first academic term, which decreased to low burnout during the second academic term but increased to high burnout during the third academic term. Using cross-sectional data, this type could be classified as a "low-burnout type" at the second academic term. These results highlight the importance of examining growth trajectories using longitudinal data, as this allows the early identification of the development of a "low-burnout type" into a "high-burnout type." Further research is needed to examine what factors distinguish the burnout types.

We did not make a direct comparison between these burnout types and those found in previous research conducted in English-speaking countries, because the current study assessed burnout using the Japanese version of the MBI, which is the standard and most frequently used burnout scale in Japan. Golembiewski et $\mathrm{al}^{39}$ found that Japanese individuals showed a higher tendency toward 
burnout relative to those of people from the United States and Canada; however, they suggested that universal norms could be inappropriate for use in the Japanese cultural context. The following factors could have given rise to the higher tendency toward burnout in Japan: 1) relative to those of American teachers, the job specifications of Japanese teachers are more complicated; ${ }^{40}$ and 2 ) schools in the United States are more likely to offer a stress management system relative to schools in Japan. In addition, a national educational association has been established in the United States. Further research is required to compare the original and Japanese versions of the MBI.

Burnout may not have been captured during the 1-year study period. Observation over a longer period may clarify the ways in which high risk of burnout occurs. In addition, there is a need to clarify whether high-stable types exist, and if they do, why.

This study considered only the level of burnout. Future studies should include the following: 1) determination of causation with respect to burnout and collaboration, and 2) examination of interventions/strategies to prevent burnout. In addition, it is necessary to examine the establishment of organizations and systems in the development of collaboration to prevent burnout.

\section{Conclusion}

In this study, observing change in burnout and collaboration over the course of a year revealed the existence of four growth trajectory combination types: low stable, moderate unstable, high unstable, and high decreasing. The results also identified inverse collaboration function. The finding that collaboration was dynamic for dynamic burnout types and stable for stable burnout types is of great interest. This was probably related to the inverse relationship between the two constructs. Of the types observed, the risk of burnout was highest for those exhibiting the high-unstable type (15\% of participants).

\section{Acknowledgments}

We express sincere thanks to the staff of the Japanese special needs schools that cooperated in the survey. This work was partly supported by JSPS KAKEN, Grant Number: 23530898.

\section{Disclosure}

The authors report no conflicts of interest in this work.

\section{References}

1. Schaufeli WB. Burnout in health care. In: Caravon P, editor. Handbook of Human Factors and Ergonomics in Health Care and Patient Safety. Mahwah, NJ: Lawrence Erlbaum; 2007:217-232.
2. Westman M, Bakker AB. Crossover of burnout among health care professionals. In: Halbesleben J, editor. Stress and Burnout in Health Care. New York, NY: Nova Sciences; 2008:111-125.

3. Tuten T. Reducing nurse burnout: a win-win situation. Huffington Post. November 26, 2012. Available from: http://www.huffingtonpost.com/teratuten/reducing-nurse-burnout_b_1916350.html. Accessed July 28, 2014.

4. Wallbank S, Hatton S. Reducing burnout and stress: the effectiveness of clinical supervision. Community Pract. 2011;84:31-35.

5. Maslach C, Jackson SE, Leiter MP. The Maslach Burnout Inventory. 3rd ed. Palo Alto, CA: Consulting Psychologists Press; 1996.

6. Schaufeli W, Enzmann D. The Burnout Companion to Study and Practice: A Critical Analysis. London and Philadelphia, PA: Taylor and Francis; 1998.

7. Motomura Y, Yatsushiro R. Factors relating to nurse burnout. Jpn Soc Occup Med Traumatol. 2010;58:120-127.

8. Arai H. "Kyoshi" hokai-burnout syokogun kokuhukunotameni [For "Teacher" Collapse-Burnout Syndrome Conquest]. Kawagoe, Japan: Suzusawa Company; 1999. Japanese.

9. Maslach C. Burnout: a multidimensional perspective. In: Schaufeli WB, Maslach C, Marek T, editors. Professional Burnout: Recent Developments in Theory and Research. Washington, DC: Taylor and Francis; 1993:19-32.

10. Onyett SR. Collaboration and the community mental health team. J Interprof Care. 1997;1:257-267.

11. Rafferty AM, Ball J, Aiken LH. Are team work and professional autonomy compatible, and do they result in improved hospital care? Qual Health Care. 2001;10(Suppl 2):ii32-ii37.

12. Ogino K. Kangoshoku niokeru Burnout-process Model no kento [Examination of the burnout process model in nursing]. Jpn Assoc Ind Organ Psychol J. 2004;17:79-90. Japanese.

13. Katsuda H. Yogogakkou nioite iryotekicare wo jissisuru kangosihi no kadai [The problem of nurses implementing medical care in schools for the disabled]. School Health Res. 2006;48:405-412. Japanese.

14. Cherniss C. Professional Burnout in Human Service Organizations. New York, NY: Praeger; 1980.

15. Golembiewski RT, Munzenrider RF, Stevenson JG. Stress in Organizations. New York, NY: Praeger; 1986.

16. Maslach C, Schaufeli WB. Historical and conceptual development of burnout. In: Schaufeli WB, Maslach C, Marek T, editors. Professional Burnout: Recent Developments in Theory and Research. Washington, DC: Taylor and Francis; 1993:1-18.

17. Shirom A. Burnout in work organization. In: Cooper CL, Robertson I, editors. International Review of Industrial and Organizational Psychology. New York, NY: Wiley; 1989:25-48.

18. Dunford BB, Shipp AJ, Boss RW, Angermeier I, Boss AD. Is burnout static or dynamic? A career transition perspective of employee burnout trajectories. J Appl Psychol. 2012;97:637-650.

19. Golembiewski RT, Munzenrider RF. Phases of psychological burnout and organizational covariants: a replication using norms from a large population. J Health Hum Resour Adm. 1984;6:290-323.

20. Montero-Marin J, Garcia-Campayo J, Mosquera Mera D, López del Hoyo YA. New definition of burnout syndrome based on Farber's proposal. J Occup Med Toxicol. 2009;4:31.

21. Nagin DS. Analyzing developmental trajectories: a semiparametric, group-based approach. Psychol Methods. 1999;4:139-157.

22. Nagin DS. Group-Based Modeling of Development. Cambridge, MA: Harvard University Press; 2005.

23. Louvet B, Gaudreau P, Menaut A, Genty J, Deneuve P. Revisiting the changing and stable properties of coping utilization using latent class growth analysis: a longitudinal investigation with soccer referees. Psychol Sport Exerc. 2009;10:124-135.

24. Ministry of Education, Culture, Sports, Science and Technology (2013). Tokubetsusiengakkou no iryoteki care nikansuruchosakekka ni tsuite [Survey results on the implementation system of medical care in special needs schools]. Survey results on the implementation system of medical care in special needs schools. Japanese. 2013. Available from: www. mext.go.jp/a_menu/shotou/tokubetu/material/1345112.htm. Accessed February 17, 2016. 
25. Maslach C, Jackson SE. The Maslach Burnout Inventory. Palo Alto, CA: Consulting Psychologists Press; 1982.

26. Kubo M. Stress to burnout tonokankei-burnout ha sutoren ka [The relationships of stresses and burnout: is burnout one of the strains?]. Jpn Assoc Ind Organ Psychol J. 1998;12:5-15.

27. Tao M, Kubo M. Burnout no riron to jissai [Theory and practice of burnout]. Tokyo, Japan: Seishin Shobo Ltd; 1996. Japanese.

28. Kanayama M, Iwai K. Iryoteki care jyujisya no kyodotasseikansyakudo no kaihatsu [Development of nurse-teacher collaboration scale]. J Child Health. 2014;78:608-612. Japanese.

29. San Martin-Rodriguez L, Beaulieu MD, D’Amour D, FerradaVidela M. The determinants of successful collaboration: a review of theoretical and empirical studies. J Interprof Care. 2005;19(Suppl 1): 132-147.

30. Muthén B, Muthén LK. M-Plus User's Guide. 6th ed. Los Angeles, CA: Muthén and Muthén; 1998-2010.

31. Arbuckle JL. Full information estimation in the presence of incomplete data. In: Marcoulides GA, Schumacher RE, editors. Advanced Structural Equation Modeling: Issues and Techniques. Mahwah, NJ: Erlbaum; 1996;243-277.

32. Little RJ. Modeling the drop-out mechanism in repeated-measures studies. J Am Stat Assoc. 1995;90:1112-1121.

33. Schwartz G. Estimating the dimensions of a model. Ann Stat. 1978;6: 461-464.

34. Halbesleben JRB. A meta-analysis of work engagement: relationships with burnout, demands, resources, and consequences. In: Bakker AB, Leiter MP, editors. Work Engagement: A Handbook of Essential Theory and Research. New York, NY: Psychology Press; 2010:102-117.
35. Lee RT, Ashforth BE. A meta-analytic examination of the correlates of the three dimensions of job burnout. J Appl Psychol. 1996;81:123-133.

36. Chang W, Ma J, Chiu H, Lin K, Lee P. Job satisfaction and perceptions of quality of patient care, collaboration and teamwork in acute care hospitals. J Adv Nurs. 2009;65:1946-1955.

37. Shimizu F. Tsujogakko nioite iryoteki care nikakawaru kangoshi nohaichi ya koyojokyo no zenkokuchosa [Actual conditions of the postings and employment of nurses for technology-dependent children at mainstream schools in Japan]. J Child Health. 2014;73:360-366. Japanese.

38. Martinussen M, Adolfsen F, Lauritzen C, Richardsen AM. Improving interprofessional collaboration in a community setting: relationships with burnout, engagement, and service quality. $J$ Interprof Care. 2012;26:219-225.

39. Golembiewski RT, Scherb K, Boudreau RA. Burnout in cross-national setting: generic and model-specific perspectives. In: Schaufeli WB, Maslach C, Marek T, editors. Professional Burnout: Recent Developments in Theory and Research. New York, NY: Taylor and Francis; 1993:217-236.

40. Nakano A, Hiruta G, Matsukura H, Tobita A, Hatsuzawa T. Chugakko no kyoshi no stress nikansuru nichibei hikaku-nippon no kyoshi wa daijobunaoka [Japan-U.S. comparison of the stress of the junior high school teacher]. Bull Contemp Educ. 2008;4:41-46. Japanese. Available from: ir.lib.fukushima-u.ac.jp/dspace/bitstream/10270/2497/1/19-49. pdf. Accessed February 17, 2016.
Psychology Research and Behavior Management

\section{Publish your work in this journal}

Psychology Research and Behavior Management is an international, peerreviewed, open access journal focusing on the science of psychology and its application in behavior management to develop improved outcomes in the clinical, educational, sports and business arenas. Specific topics covered include: Neuroscience, memory \& decision making; Behavior

\section{Dovepress}

modification \& management; Clinical applications; Business \& sports performance management; Social and developmental studies; Animal studies. The manuscript management system is completely online and includes a quick and fair peer-review system. Visit http://www.dovepress. com/testimonials.php to read real quotes from published authors. 